\title{
Review \\ Coupling metal oxide nanoparticle catalysts for water oxidation to molecular light absorbers
}

\author{
Heinz Frei* \\ Molecular Biophysics and Integrated Bioimaging Division, Lawrence Berkeley National \\ Laboratory, University of California, Berkeley, CA 94720, USA
}

*Corresponding author. E-mail: HMFrei@lbl.gov. 


\begin{abstract}
Water oxidation, as a mandatory reaction of solar fuels conversion systems, requires the use of light absorbers with electronic properties that are well matched with those of the multi-electron catalyst in order to achieve high efficiency. Molecular light absorbers offer flexibility in fine tuning of orbital energetics, and metal oxide nanoparticles have emerged as robust oxygen evolving catalysts. Hence, these materials choices offer a promising approach for the development of photocatalytic systems for water oxidation. However, efficient charge transfer coupling of molecular light absorbers and metal oxide nanoparticle catalysts has proven a challenge. Recent new approaches towards the efficient coupling of these components based on synthetic design improvements combined with direct spectroscopic observation and kinetic evaluation of charge transfer processes are discussed.
\end{abstract}

Keywords: Water oxidation catalysts; Metal oxides; Molecular light absorbers; Artificial photosynthesis; Charge transfer; Electronic coupling 


\section{Introduction}

Efficient water oxidation driven by sunlight is an essential reaction for any solar fuel conversion system because it provides the electrons and protons needed for converting carbon dioxide to a liquid transportation fuel. The necessity of using water as donor stems from the requirement that a solar fuels technology on the terawatt scale be completely cyclic, with no major side products accumulating at the fuels generation or consumption stage. Because carbon dioxide and water are always the end products of spent fuel, electrons and protons need to be taken from water in order for the fuels generation-utilization process to be cyclic. Metal oxides of late first row transition elements $\mathrm{Co}, \mathrm{Mn}, \mathrm{Fe}, \mathrm{Ni}$, and some multi-metal variants have recently emerged as water oxidation catalysts with sufficiently high activity for incorporation into solar fuel conversion systems. These oxides are attractive because of robustness and Earth abundance, which are essential for scalability. Breakthroughs in nanostructuring of these metal oxides have led to dramatic enhancement of the number of catalytic surface sites per geometrical area [1-14] resulting in nanoparticulate or nanostructured metal oxide catalysts that operate at sufficiently high rates to keep up with the photon flux impinging on the catalyst at maximum solar intensity $\left(1,500\right.$ photons $\left.\mathrm{s}^{-1} \mathrm{~nm}^{-2}\right)$ [15], a key requirement for an efficient artificial photosystem.

For efficient coupling of metal oxide catalysts, molecular light absorbers offer a distinct advantage over semiconductor light absorbers in terms of the fine tuning of the redox properties. This allows the precise matching of the redox potential of the sensitizer and the catalyst for maximum conversion of solar photon energy into chemical energy of the reduced fuel product and evolving oxygen. Furthermore, the light absorber-catalyst contact can be designed and controlled at the atomic level by covalent anchoring methods or specific electrostatic 
interactions, while solid-solid interfaces of semiconductor light absorbers and metal oxide catalysts typically cannot. Efficient coupling is important for achieving high quantum yield of charge transfer from light absorber to catalyst.

A particular challenge of light-driven multi-electron catalysis is matching of the rate of photon absorption by the chromophore with the speed of multi-electron catalysis in order to maximize the productive use of absorbed light. While average turnover frequencies per exposed surface metal of oxide catalysts for water oxidation are on the order of $10^{-2} \mathrm{O}_{2} \mathrm{~s}^{-1}[1,16-18]$, the very high density of sites per geometrical area of a nanostructured catalyst offers productive use of every charge generated by an absorbed photon even at high solar flux because there is a sufficient number of sites at disposal to start a fresh catalytic cycle. However, a persistent challenge for molecular light absorber-metal oxide catalyst systems, particularly for the water oxidation half reaction, is to achieve high thermodynamic and quantum efficiency for charge transfer between the light absorber and the catalyst. In this article, we will review recent progress towards efficient coupling of molecular light absorber-metal oxide nanoparticle catalyst assemblies for visible light-driven water oxidation.

\section{All-inorganic binuclear light absorber-metal oxide nanoparticle catalyst systems}

Oxo-bridged hetero binuclear units anchored on silica are molecularly defined visible light absorbers that can be coupled to nanoparticle water oxidation catalysts by selective assembly methods. These all-inorganic binuclear units possess a metal-to-metal charge-transfer absorption (MMCT) extending from the UV deep into the visible spectral region, as shown for a $\mathrm{ZrOCo}^{\mathrm{II}}$ unit anchored on a mesopore silica surface in Figure 1(a) $[19,20]$. Absorption of a photon by the 
MMCT transition results in electron transfer from a HOMO of the $\mathrm{Co}^{\mathrm{II}}$ donor to the LUMO of the $\mathrm{Zr}^{\mathrm{IV}}$ acceptor (Figure $1 \mathrm{~b}$ ). Transient $\mathrm{Co}^{\mathrm{III}}$ so produced has sufficient oxidation power to drive a water oxidation catalyst. Recent syntheses of a dozen different hetero binuclear units featuring Earth abundant transition and some group IIIA-VIA metals [21] provide a wide range of light absorbers with flexible choice of redox potential of the donor center. This allows matching of the redox potential of the light absorber with that of the water oxidation catalyst. For systems studied thus far by transient optical spectroscopy, such as $\mathrm{TiOMn}^{\mathrm{II}}$ and $\mathrm{TiOCu}^{\mathrm{I}}$, excited MMCT lifetimes extend to microseconds, which should be adequate for driving multi-electron catalysts for water oxidation [22-24].

(a)
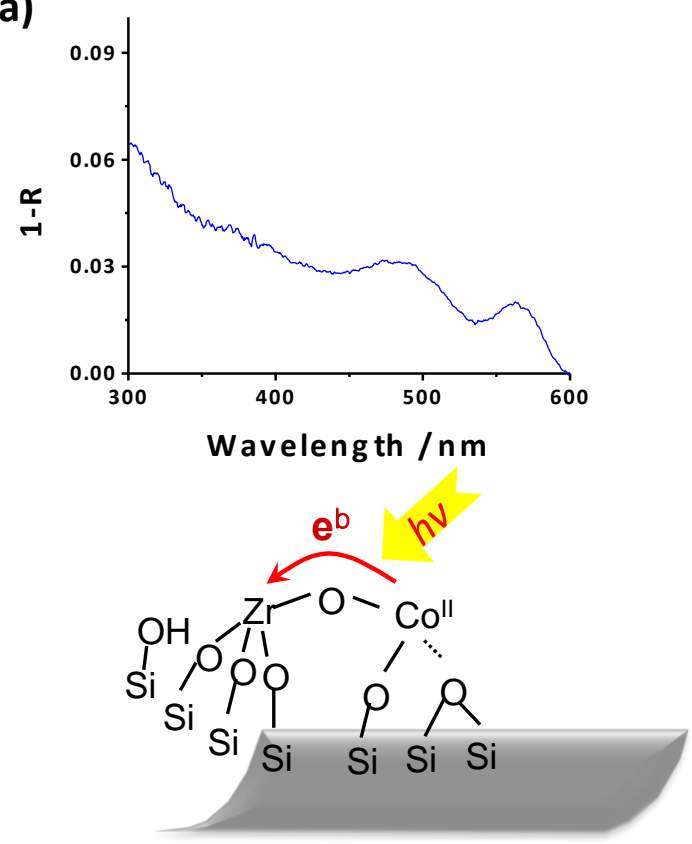

(b)
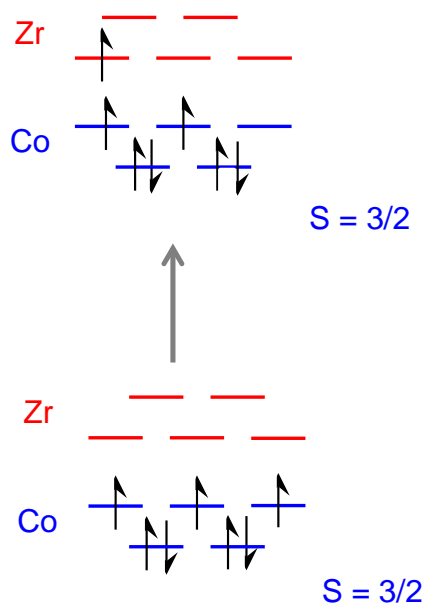

Fig. 1. ZrOCo metal-to-metal charge-transfer unit covalently anchored on silica mesopore surface (SBA-15). (a) Optical absorption of binuclear ZrOCo unit measured by diffuse reflectance spectroscopy. The absorption of Co was subtracted using the spectrum of monometallic Co-SBA-15. From Ref. [19], with permission. (b) Orbital occupancy change upon optical MMCT excitation.

\subsection{Driving Ir oxide nanoparticle catalyst with TiOCr light absorber}


In an early example, TiOCr units anchored in the pore surface of mesoporous silica MCM-41 (unidimensional silica structure of $3 \mathrm{~nm}$ diameter channels, here with $\mathrm{Al}$ as minor substituent $(\mathrm{Al} / \mathrm{Si}=0.04)$ for stable anchoring of $\mathrm{Cr}$ centers $)$ were coupled to Ir oxide nanoclusters of $2 \mathrm{~nm}$ diameter using a chemical deposition method based on the redox properties of $\mathrm{Cr}$ centers and organometallic Ir precursor [25]. Ir oxide nanoparticles in the form of aqueous colloids or nanoclusters supported on mesoporous silica or anodes are known as efficient water oxidation catalysts [26-28]. The coupling was achieved by spontaneous redox reaction of $\operatorname{Ir}^{\mathrm{III}}(\mathrm{acac})_{3}$ precursor $(\mathrm{acac}=$ acetylacetonate $)$ in solution at room temperature with $\mathrm{Cr}$ centers of $\mathrm{TiOCr}^{\mathrm{V}}$ units in MCM-41, resulting in the formation of $\mathrm{TiOCr}^{\mathrm{III}}$ with adjacent $\mathrm{Ir}^{\mathrm{IV}}(\mathrm{acac})_{2}$ as manifested by FT-IR, FT-Raman and UV-vis spectroscopic monitoring [25]. The loss of acac ligand upon oxidation of the precursor to $\operatorname{Ir}^{\mathrm{IV}}$ observed in the infrared and optical spectra created a nucleus for growth of Ir oxide nanocluster upon mild calcination at $350{ }^{\circ} \mathrm{C}$. While the proximity of the $\mathrm{TiOCr}^{\mathrm{III}}$ charge transfer light absorber and the $\mathrm{IrO}_{x}$ clusters cannot be directly demonstrated spectroscopically (the bridge mode of a Cr-O-Ir linkage was detected by FT-Raman at $808 \mathrm{~cm}^{-1}$ when starting with single $\mathrm{Cr}$ centers, however) [29], photochemical studies discussed in the following established that the catalyst cluster is positioned in electron transfer distance from the $\mathrm{Cr}$ donor center of the $\mathrm{TiOCr}$ unit. The proximity of the $\mathrm{IrO}_{x}$ cluster is most probably due to the fact that the ligand-deficient Ir center that serves as nucleus for growth is generated in charge transfer distance from the $\mathrm{Cr}$ center (nanometer or less).

Excitation of the $\mathrm{Ti}^{\mathrm{IV}} \mathrm{OCr}^{\mathrm{III}} \rightarrow \mathrm{Ti}^{\mathrm{III}} \mathrm{OCr}^{\mathrm{IV}}$ absorption of TiOCr-IrO${ }_{x}$ units in mesoporous silica particles suspended in close to neutral aqueous solution with $458 \mathrm{~nm}$ light resulted in water oxidation to $\mathrm{O}_{2}$, which was monitored in solution by an $\mathrm{O}_{2}$-sensitive Clark electrode, [25]. As a 
half reaction, the system required a sacrificial electron acceptor such as persulfate which reoxidized transient $\mathrm{Ti}^{\mathrm{III}}$, as shown in Figure 2. The observation of visible light driven water oxidation by excitation of the $\mathrm{Ti}^{\mathrm{iII}} \mathrm{OCr}^{\mathrm{IV}}-\mathrm{IrO}_{x}$ state is consistent with the estimated redox potential of $2 \mathrm{~V}$ for transient $\mathrm{Cr}^{\mathrm{IV}}$. From the remarkably high quantum yield of 13 percent, efficient electron transfer coupling of the $\mathrm{Cr}$ donor center with the Ir oxide catalyst is inferred. The result was confirmed by the observation of $\mathrm{Ti}^{\mathrm{III}}$ by EPR spectroscopy that accumulates during photocatalysis when the persulfate acceptor was omitted, indicating that hole transfer from transient $\mathrm{Ti}^{\mathrm{III}} \mathrm{OCr}^{\mathrm{IV}}$ to the Ir oxide catalyst cluster competes successfully with back electron transfer of $\mathrm{Ti}^{\mathrm{III}}$. Once the $\mathrm{Cr}$ center captured an electron from $\mathrm{IrO}_{x}, \mathrm{Ti}^{\mathrm{III}}$ has no open electron transfer path and is rendered sufficiently long lived for detection by EPR spectroscopy. The

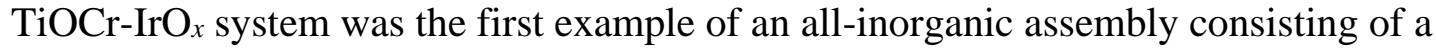
molecularly defined single photon, single charge transfer pump driving a multi-electron catalyst for water oxidation.
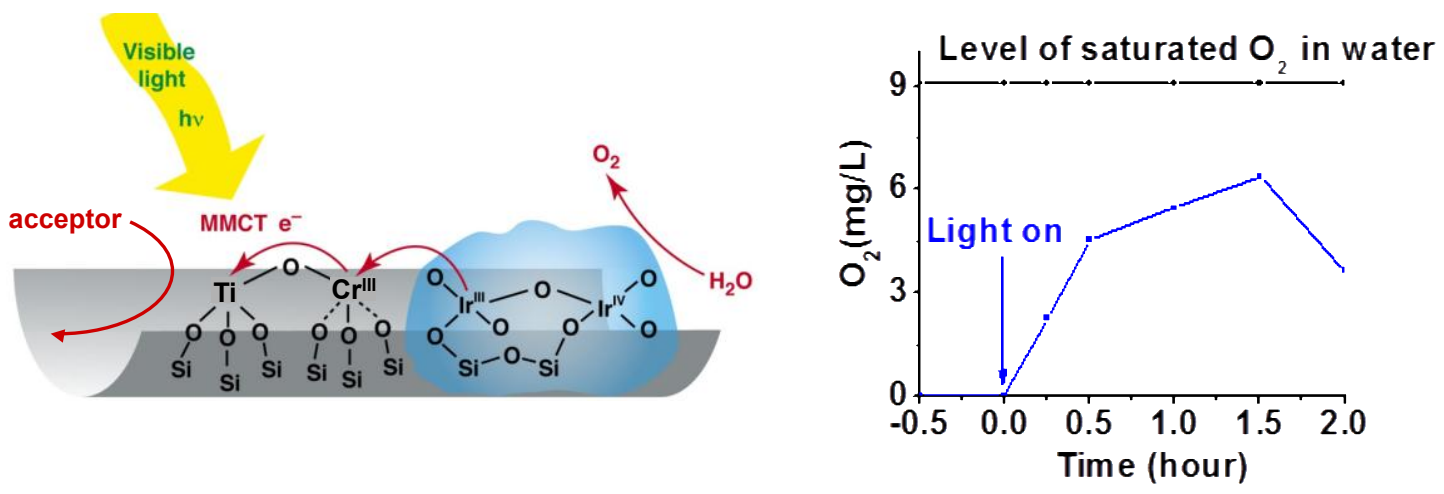

Fig. 2. TiOCr ${ }^{\mathrm{III}}-\mathrm{IrO}_{x}$ photocatalytic unit for water oxidation. Electrochemical monitoring of $\mathrm{O}_{2}$ evolution upon illumination of the $\mathrm{Ti}^{\mathrm{IV}} \mathrm{OCr}^{\mathrm{III}} \rightarrow \mathrm{Ti}^{\mathrm{III}} \mathrm{OCr}^{\mathrm{IV}} \mathrm{MMCT}$ transition at $458 \mathrm{~nm}$. The sample is an aqueous suspension of MCM- 41 mesoporous silica particles containing $\mathrm{TiOCr}^{\mathrm{III}}$ $\mathrm{IrO}_{x}$ units. The electron on transient $\mathrm{Ti}^{\mathrm{III}}$ is transferred to sacrificial persulfate acceptor. From Ref. [25], with permission.

\subsection{Coupling water oxidation to carbon dioxide reduction at ZrOCo-Ir oxide unit}


By expanding the approach of redox reaction with precursor metal complexes for the spatially controlled positioning of Ir oxide catalyst clusters to light-driven instead of dark processes, it became feasible to assemble a $\mathrm{ZrOCo}^{\mathrm{II}}$-IrO $x$ unit that not only affords photo-induced water oxidation, but converts $\mathrm{CO}_{2}$ to $\mathrm{CO}$ by reduction at transient $\mathrm{Zr}^{\mathrm{III}}$ formed upon MMCT excitation. Carbon dioxide reduction was previously demonstrated for $\mathrm{ZrOCo}^{\mathrm{II}}$ units anchored in mesoporous silica SBA-15 (unidimensional channels of $8 \mathrm{~nm}$ pore diameter) loaded with $1 \mathrm{~atm}$ of $\mathrm{CO}_{2}$ gas upon illumination of the MMCT transition in the presence of an amine as sacrificial donor [19]. Hence, $\mathrm{ZrOCo}^{\mathrm{II}}-\mathrm{IrO}_{x}$ units were shown to close the photosynthetic cycle of $\mathrm{CO}_{2}$ reduction by $\mathrm{H}_{2} \mathrm{O}$ [20]. In contrast to the $\mathrm{TiOCr}^{\mathrm{V}}$ site discussed above, the Co donor center of ground state $\mathrm{ZrOCo}^{\mathrm{II}}$ unit does not have sufficient oxidation power to spontaneously oxidize $\mathrm{aIr}^{\mathrm{III}}(\mathrm{acac})_{3}$ species in the vicinity. However, transient $\mathrm{Co}^{\mathrm{III}}$ formed upon excitation of the $\mathrm{Zr}^{\mathrm{IV}} \mathrm{OCo}^{\mathrm{II}} \rightarrow \mathrm{Zr}^{\mathrm{III}} \mathrm{OCo}{ }^{\mathrm{III}}$ transition possesses sufficiently positive potential $(1.8 \mathrm{~V})$ to oxidize the precursor to $\operatorname{Ir}^{\mathrm{IV}}$ (acac) $)_{2}$ under loss of acac ligand as evidenced by the optical and FT-IR spectra. Figure 3(a) shows the UV-Vis spectra upon photodeposition of the Ir precursor by $458 \mathrm{~nm}$ illumination, with the detached ligand appearing at $299 \mathrm{~nm}$ (shown in inset of Figure 3(a) for clarity). An identical photodeposition experiment monitored by FT-IR shows bands of free acac emerging at 1587 and $1507 \mathrm{~cm}^{-1}$, and of $\left[\mathrm{Ir}^{\mathrm{IV}}(\mathrm{acac})_{2}\right]^{2+}$ at $1361 \mathrm{~cm}^{-1}$ (Figure 3b) [20]. Similar to the assembly of the $\mathrm{TiOCr}-\mathrm{IrO}_{x}$ system, subsequent mild calcination resulted in the formation of $2 \mathrm{~nm}$ sized $\mathrm{IrO}_{x}$ catalyst adjacent to the Co donor center by virtue of cluster growth around a ligand-deficient a $\mathrm{Ir}^{\mathrm{IV}}$ center. 

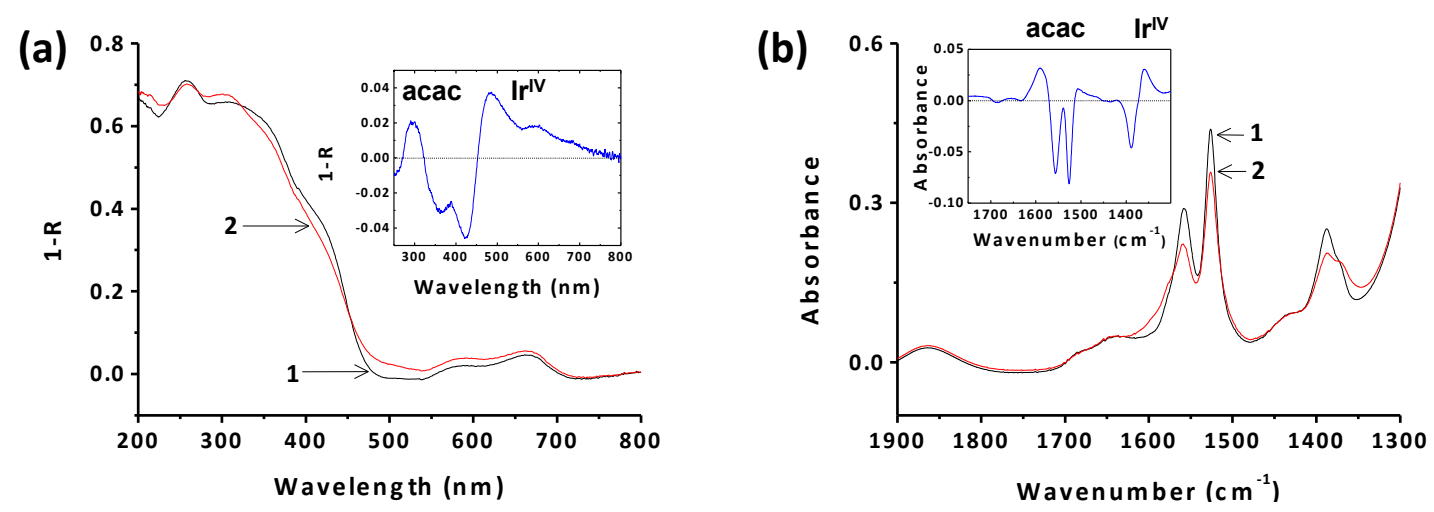

Fig. 3. Photodeposition of $\operatorname{Ir}(\mathrm{acac})_{3}$ precursor under loss of acac ligand. (a) UV-Vis DRS of ZrOCo SBA-15 loaded with Ir ${ }^{\text {III }}$ (acac) ${ }_{3}$ before (trace 1, black) and after $1 \mathrm{~h}$ photodeposition with $458 \mathrm{~nm}$ Ar ion laser emission $\left(460 \mathrm{~mW} / \mathrm{cm}^{2}\right)$ under vacuum (trace 2, red). Inset: Difference spectrum (2) - (1). The growth at $299 \mathrm{~nm}$ shows formation of free acac ligand. (b) FT-IR spectra of ZrOCo SBA-15 loaded with Ir ${ }^{\text {III }}$ (acac) $)_{3}$ before (trace 1, black) and after $1 \mathrm{~h}$ photodeposition with $458 \mathrm{~nm}$ emission $\left(460 \mathrm{~mW} / \mathrm{cm}^{2}\right)$ of an Ar ion laser in vacuum (trace 2, red). Inset: Difference FT-IR spectrum (2) - (1). From Ref. [20], with permission.

As shown in Figure 4(a), illumination at $355 \mathrm{~nm}$ of the ZrOCo light absorber of powders of SBA-15 containing $\mathrm{ZrOCo}{ }^{\mathrm{II}}-\mathrm{IrO} x$ units that were loaded with a gas mixture of ${ }^{13} \mathrm{CO}_{2}$ (760 Torr) and $\mathrm{H}_{2} \mathrm{O}$ (100 mTorr) exhibited growth of ${ }^{13} \mathrm{CO}$, monitored by the gas phase infrared rovibrational bands. Evolution of $\mathrm{O}_{2}$ was detected by mass spectroscopy. For experiments with isotopic modifications $\mathrm{H}_{2}{ }^{18} \mathrm{O}$ and ${ }^{13} \mathrm{C}^{16} \mathrm{O}_{2}$, both ${ }^{18} \mathrm{O}_{2}$ and ${ }^{16} \mathrm{O}_{2}$ were detected, but no partially labeled ${ }^{18} \mathrm{O}^{16} \mathrm{O}$ (Figure 4b). These observations confirm that water is the electron source for $\mathrm{CO}_{2}$ reduction. Furthermore, the results suggests that the reaction mechanism of water oxidation catalysis on the Ir oxide nanoparticle surface, which produces ${ }^{18} \mathrm{O}_{2}$, does not share the reaction path with dissociating ${ }^{16} \mathrm{O}$ of $\mathrm{CO}_{2}$ that leads to the formation of ${ }^{16} \mathrm{O}_{2}$. The importance of the spatially directed photodeposition step for achieving proper coupling of Ir oxide nanocluster catalysts with ZrOCo light absorber is manifested by the fact that no reaction is observed when conducting the irradiation experiment with SBA-15 samples that featured randomly arranged 
$\mathrm{ZrOCo}$ units and $\mathrm{IrO}_{x}$ clusters. The quantum efficiency of 17 percent (at $355 \mathrm{~nm}$ ) implies that hole transfer from the Co center of excited $\mathrm{Zr}^{\mathrm{III}} \mathrm{OC}{ }^{\mathrm{III}}$ to $\mathrm{IrO}_{x}$ nanocluster competes rather successfully with $\mathrm{Zr}^{\mathrm{III}} \mathrm{OCo}^{\mathrm{III}} \rightarrow \mathrm{Zr}^{\mathrm{IV}} \mathrm{OCo}^{\mathrm{II}}$ back electron transfer. While the $\mathrm{ZrOCo}$ unit reduces $\mathrm{CO}_{2}$ under blue light if a sacrificial donor is used [19], visible light illumination (458 nm, $\mathrm{Ar}$ ion laser) of the $\mathrm{ZrOCo}^{\mathrm{II}}-\mathrm{IrO}_{x}$ unit that uses $\mathrm{H}_{2} \mathrm{O}$ as electron source did not result in detectable products.

(a)

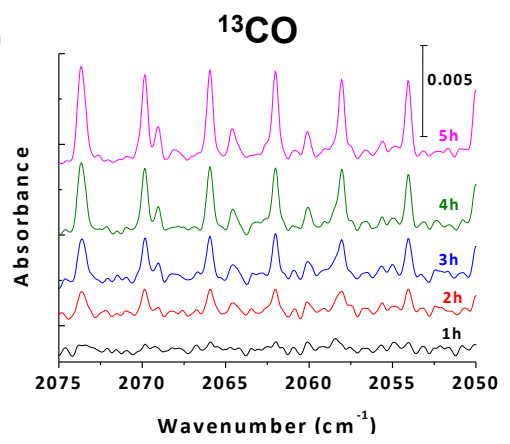

(b)

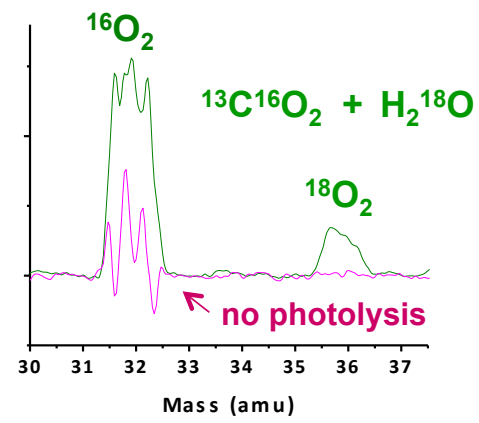

Fig. 4. Photoreduction of ${ }^{13} \mathrm{CO}_{2}$ by $\mathrm{H}_{2} \mathrm{O}$ at $\mathrm{ZrOCo}-\mathrm{IrO}_{x}$ units in SBA-15. (a) Ro-vibrational FTIR spectra of growing gas phase ${ }^{13} \mathrm{CO}$ product upon irradiation at $355 \mathrm{~nm}$ in the presence of ${ }^{13} \mathrm{CO}_{2}$ and $\mathrm{H}_{2} \mathrm{O}$ gas mixture. (b) Mass spectrometric monitoring of oxygen evolution at $\mathrm{ZrOCo}-$ $\mathrm{IrO}_{x}$ SBA-15 loaded with ${ }^{13} \mathrm{C}^{16} \mathrm{O}_{2}$ and $\mathrm{H}_{2}{ }^{18} \mathrm{O}$. Control spectrum of gas loaded sample without illumination is also shown. From Ref. [20], with permission.

Transient optical studies of the ZrOCo system currently in progress in our lab attempt to gain detailed insight into the photophysical mechanism that enables hole transfer to the catalyst to compete with back electron transfer. We speculate that ultrafast intersystem crossing from the 
optically excited high spin $\mathrm{Zr}^{\mathrm{III}} \mathrm{OC}{ }^{\mathrm{III}}(\mathrm{S}=3 / 2)$ to a low spin $\mathrm{S}=1 / 2$ plays a role, which would result in slow back electron transfer because of spin change required to regenerate high spin $\mathrm{Zr}^{\mathrm{IV}} \mathrm{OCo}^{\mathrm{II}}(\mathrm{S}=3 / 2)$ ground state. Such a mechanism was proposed on the basis of our recent transient optical study of $\mathrm{TiOMn}^{\mathrm{II}}$ units where the temperature dependence of the slow back electron transfer of $2 \mu$ s upon visible light excitation of the $\mathrm{Ti}^{\mathrm{iV}} \mathrm{OMn}^{\mathrm{II}}(\mathrm{S}=5 / 2) \rightarrow \mathrm{Ti}^{\mathrm{iI}} \mathrm{OMn}^{\mathrm{III}}$ $(\mathrm{S}=5 / 2)$ revealed an electronic coupling constant of just $0.22 \mathrm{~cm}^{-1}$ [22]. The very small coupling constant is indicative of a spin forbidden electronic transition upon back electron transfer, most likely a consequence of ultrafast intersystem crossing of the optically excited high spin $\mathrm{S}=5 / 2$ state to a low spin $\mathrm{S}=3 / 2$ (or even $\mathrm{S}=1 / 2$ ) MMCT state. The thermally relaxed low spin MMCT state so formed requires spin change upon back electron transfer to high spin ground state, a process that is sufficiently slow for hole transfer from the oxidized donor center to a catalyst to become competitive. In the case of the $\mathrm{ZrOCo}-\mathrm{IrO}_{x}$ assembly, once the Co is reduced, back transfer of the electron from $\mathrm{Zr}{ }^{\mathrm{III}}$ is blocked, rendering the reduced $\mathrm{Zr}$ sufficiently long lived to activate $\mathrm{CO}_{2}$.

A similar case of very slow back electron transfer of $9.8 \mu$ s upon visible light excitation of an oxo-bridged system consisting the complex $\mathrm{C}_{5} \mathrm{H}_{5}-\mathrm{RuH}$ covalently attached to a $\mathrm{TiO}_{2}$ nanoparticle surface (anatase) was recently reported by Long [30]. The long residence time of electrons on $\mathrm{TiO}_{2}$ uponphoto-induced $\mathrm{Ru}^{\mathrm{II}}-\mathrm{O}-\mathrm{TiO}_{2}$ metal-to-particle charge-transfer affords $\mathrm{CO}_{2}$ reduction to methane while water is oxidized to $\mathrm{O}_{2}$ at the $\mathrm{Ru}$ center, as demonstrated by ${ }^{13} \mathrm{C}$ and ${ }^{18} \mathrm{O}$ isotopic labeling. Femtosecond infrared spectroscopy confirmed direct optical electron transfer from Ru center to $\mathrm{TiO}_{2}$ particle [30]. 
The photodeposition method for coupling hetero binuclear light absorbers to metal oxide nanocluster catalysts has recently been expanded to the reduction (acceptor) side of these units. Spatially directed growth of a cuprous oxide nanocluster catalyst adjacent to the $\mathrm{Zr}$ center of $\mathrm{ZrOCo}^{\mathrm{II}}$ units in mesoporous silica was accomplished by photoexcitation of the MMCT absorption in the presence of $\mathrm{Cu}^{\mathrm{II}}\left(\mathrm{NCCH}_{3}\right)_{4}$ precursor. Conversion to $\mathrm{Cu}^{\mathrm{I}}\left(\mathrm{NCCH}_{3}\right)_{n}(n \leq 3)$ by electron transfer from transient $\mathrm{Zr}^{\mathrm{III}}$ was observed by UV-vis and FT-IR spectroscopy, as shown in Figure 5(a) and 5(b) [31]. Here, the electrons are provided by a co-adsorbed amine donor that instantly reduces transient $\mathrm{Co}^{\mathrm{III}}$ formed upon excitation of the MMCT transition. Similar to the case of spatially directed Ir oxide cluster synthesis, ligand-deficient $\mathrm{Cu}^{\mathrm{I}}$ complex so formed is thought to act as nucleus for growth of nanosized $\mathrm{Cu}$ oxide clusters $(3 \mathrm{~nm})$, as shown in Figure 5(c) and 5(d). Photo-induced reduction of gas phase $\mathrm{CO}_{2}$ at the $\mathrm{Cu}_{x} \mathrm{O}_{y}-\mathrm{ZrOCo}^{\mathrm{II}}$ units was found to strongly depend on the oxidation state of the surface $\mathrm{Cu}$ centers on the nanocluster surface, which was determined by the frequency of the $\mathrm{CO}$ infrared mode when probing adsorbed $\mathrm{CO}$ onto the $\mathrm{Cu}_{x} \mathrm{O}_{y}$ surface [31]. Clusters with predominantly metallic $\mathrm{Cu}^{0}$ on the surface, generated by photodriven electron transfer when illuminating the $\mathrm{ZrOCo}_{\mathrm{IrO}}$ unit in the absence of $\mathrm{CO}_{2}$, gave 3-fold higher rates for $\mathrm{CO}_{2}$ photoreduction to $\mathrm{CO}$ than clusters with predominantly surface $\mathrm{Cu}^{\mathrm{II}}$. This finding presents compelling evidence that $\mathrm{CO}_{2}$ is reduced by the $\mathrm{Cu}_{x} \mathrm{O}_{y}$ nanocluster as the ZrOCo light absorber transfers electrons to the catalyst cluster, demonstrating an allinorganic polynuclear unit that efficiently couples a single photon, single charge transfer light absorber to a multi-electron catalyst for $\mathrm{CO}_{2}$ reduction. 
(a)

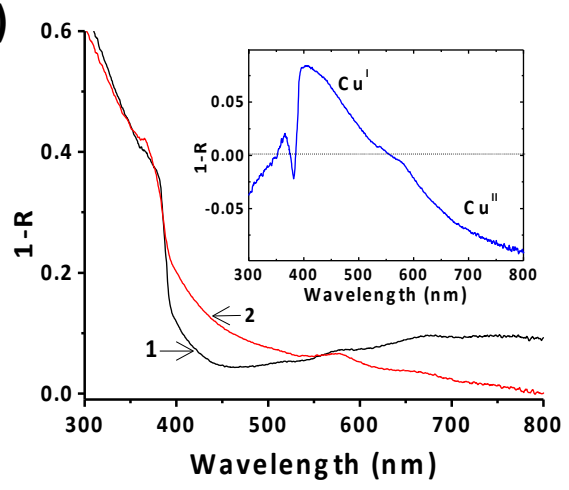

(c)

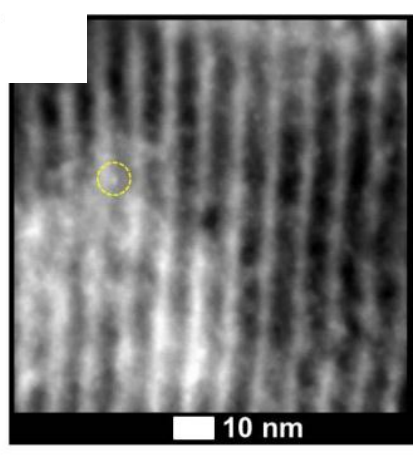

(b)

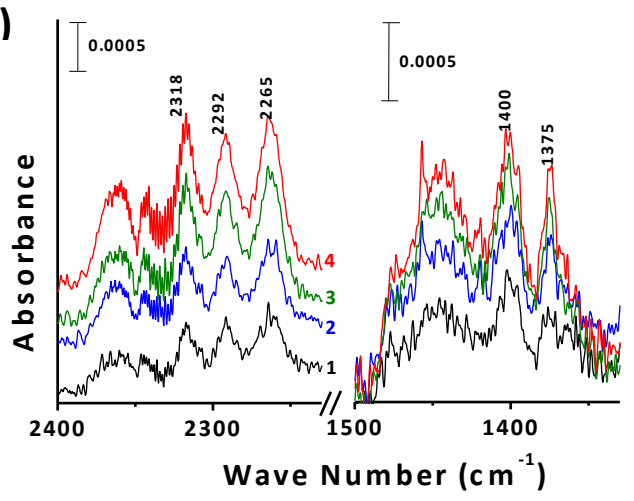

(d)

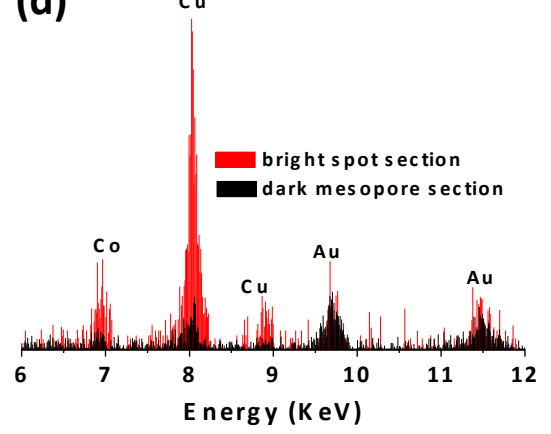

Fig. 5. $\mathrm{Cu}_{x} \mathrm{O}_{y}-\mathrm{ZrOCo}$ "II photocatalytic unit for $\mathrm{CO}_{2}$ reduction assembled on the surface of mesoporous silica SBA-15. (a) UV-vis DRS of $\mathrm{ZrOCo}{ }^{\mathrm{II}} \mathrm{SBA}-15$ loaded with $\left[\mathrm{Cu}^{\mathrm{I}}\left(\mathrm{NCCH}_{3}\right)_{4}\right]^{+}$ after air oxidation for conversion to $\mathrm{Cu}^{\text {II }}$ (trace 1 , black), followed by $1 \mathrm{~h}$ of photodeposition at $355 \mathrm{~nm}\left(100 \mathrm{~mW} / \mathrm{cm}^{2}\right)$ (trace 2, red). Inset: Difference spectrum (2) - (1). (b) Difference FT-IR spectra of $\mathrm{ZrOCo}{ }^{\mathrm{II}}$-SBA-15 sample loaded with $\left[\mathrm{Cu}^{\mathrm{I}}\left(\mathrm{NCCH}_{3}\right)_{4}\right]^{+}$after air oxidation to $\mathrm{Cu}$, recorded before and after photodeposition using $458 \mathrm{~nm}$ irradiation $\left(190 \mathrm{~mW} / \mathrm{cm}^{2}\right)$ for $15 \mathrm{~min}$ (trace 1, black), $30 \mathrm{~min}$ (trace 2, blue), $45 \mathrm{~min}$ (trace 3, green), and $60 \mathrm{~min}$ (trace 4, red). The infrared bands show the growth of detached (free) acetonitrile ligands. (c) High angle annular dark field (HAADF) images of $\mathrm{Cu}_{x} \mathrm{O}_{y}-\mathrm{ZrOCo}{ }^{\text {II }} \mathrm{SBA}-15$ and (d) EDX spectra of Cu bright spot and dark mesopore section of image (a). Au signals are due to the use of a gold grid. From Ref. [31], with permission.

\section{Organometallic light absorber-metal oxide nanoparticle catalyst system}

The first detailed studies of charge transfer of an organometallic light absorber coupled to a metal oxide nanoparticle catalyst by transient optical spectroscopy were reported by Mallouk, which involved $\left[\mathrm{Ru}(\mathrm{bpy})_{3}\right]^{2+}\left(\mathrm{bpy}=2,2^{\prime}\right.$-bipyridyl) and colloidal $\mathrm{IrO}_{2}$ particles in aqueous 
solution [32,33]. In this assembly, the Ru dye was anchored by malonate groups on the metal oxide catalyst and at the same time attached by phosphonate groups to a $\mathrm{TiO}_{2}$ film, as shown in Figure 6(a). Upon visible light excitation of the $\mathrm{Ru}$ dye and electron injection into $\mathrm{TiO}_{2}$, the hole transfer time of $2.2 \mathrm{~ms}$ from the oxidized sensitizer to the metal oxide cluster was directly measured by the recovery of the reduced sensitizer (Figure 6b). While the rate is modest, relevant in terms of efficiency of the photo-induced water oxidation half reaction is the branching between this productive forward charge transfer from excited light absorber to the catalyst and competing, efficiency degrading back reactions. With the latter occurring much faster than forward hole transfer to the catalyst (Figure 6b), a relay akin to the tyrosine-histidine bridge between the $\mathrm{Mn}_{4} \mathrm{O}_{4}$ catalyst cluster and porphyrin $\mathrm{P}_{680}$ light absorber of Photosystem II was introduced [33-35]. The role of the relay is to reduce the oxidized light absorber to its starting state before the competing reduction by back transfer of the excited electron can occur. This would give the oxidized relay sufficient time forhole transfer to the metal oxide catalyst while preventing reduction of the light absorber by back electron transfer. Covalent attachment of a benzimidazole-phenol relay to the $\mathrm{IrO}_{2}$ catalyst particle and positioning of the unit adjacent to the $\mathrm{Ru}$ light absorber on a $\mathrm{TiO}_{2}$ electrode surface as depicted in Figure 6(c) resulted in an approx. 3-fold increase of the rate of hole transfer from $\left[\mathrm{Ru}(\mathrm{bpy})_{3}\right]^{3+}$ to $\mathrm{IrO}_{2}$ catalyst [34]. Further improvement of this construct is anticipated when introducing covalent or other well defined coupling of the benzimidazole-phenol relay and the light absorber, which is not yet implemented in the current assembly [33,34]. 
(a)

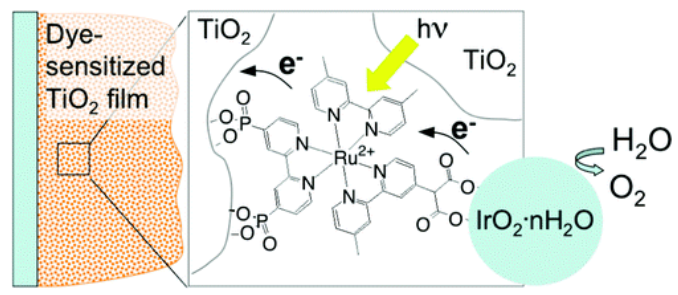

(b)

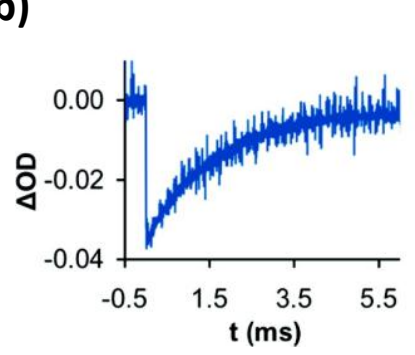

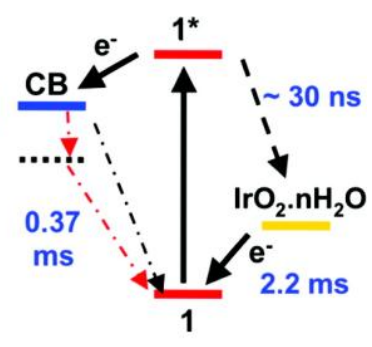

(c)

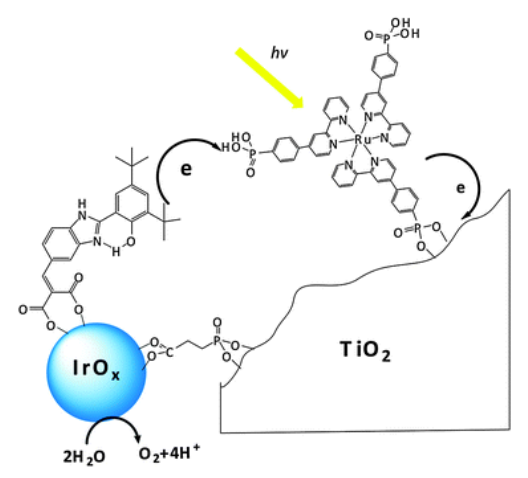

Fig. 6. Ru dye sensitizer-Ir oxide nanocluster assembly for visible light driven water oxdiation. (a) Sensitizer- $\mathrm{IrO}_{2}$ nanocatalyst assembly anchored on $\mathrm{TiO}_{2}$ surface. (b) Bleach recovery of $\mathrm{Ru}$ sensitizer at $470 \mathrm{~nm}$ upon excitation at $532 \mathrm{~nm}$. $\mathrm{CB}$, conduction band of $\mathrm{TiO}_{2}$. The dashed line indicates surface trap states on $\mathrm{TiO}_{2}$. From Ref. [32], with permission. (c) Benzimidazole-phenol redox relay for increasing the quenching rate of the oxidized Ru light absorber. From Ref. [34], with permission.

Envisioning a dye-sensitized photoelectrochemical cell design that exploits the established ultrafast transfer of photo-excited electrons from Ru polypyridyldye molecules to $\mathrm{TiO}_{2}$, the $\mathrm{Ru}(\text { bpy })_{3}-\mathrm{IrO}_{2}$ photocatalytic assembly was anchored on a $\mathrm{TiO}_{2}$ anode surface. The competition between hole transfer from the oxidized light absorber to the $\mathrm{IrO}_{2}$ catalyst and back reaction of the electron injected into $\mathrm{TiO}_{2}$ was evaluated by transient electrochemical measurements of the charge transfer rates. Potential-step chronoabsorptometry allowed the determination of the rate constant for charge transfer between the oxidized sensitizer and catalyst, while transient open circuit photovoltage decay measurements revealed rate constants 
for back transfer of the injected electron on $\mathrm{TiO}_{2}$ to oxidized dye and to $\mathrm{IrO}_{2}$ catalyst. The highest measured hole transfer yields were 13 percent [36]. Electrons stabilized in the $\mathrm{TiO}_{2}$ film by intercalated protons were identified as the main cause of undesired back electron transfer. This mechanistic insight offers guidance for improvement of the $\mathrm{TiO}_{2}$ anchored molecular light absorber-Ir oxide nanocatalyst system.

\section{Molecular light absorber-metal oxide catalyst coupled by organic wires embedded in nanoscale silica separation membrane}

\subsection{Synthesis and structure of assembly}

While the $\mathrm{ZrOCo}-\mathrm{IrO}_{x}$ assembly affords $\mathrm{CO}_{2}$ photoreduction by $\mathrm{H}_{2} \mathrm{O}$ on the nanoscale, the sites of oxidation and reduction catalysis are not yet separated by a membrane. Separation is imperative in particular for artificial photosystems that generate liquid fuel products like methanol because crossover of reduction and oxidation intermediates would instantly degrade the conversion efficiency. To introduce a membrane while enabling closure of the photosynthetic cycle on the nanoscale, we are developing core-shell nanotube arrays in which each nanotube operates as a complete, independent photosystem for the conversion of $\mathrm{CO}_{2}$ and $\mathrm{H}_{2} \mathrm{O}$ to fuel. As indicated in the cartoon of Figure 7(a), the core is a $\mathrm{Co}_{3} \mathrm{O}_{4}$ nanotube serving as water oxidation catalyst while the surrounding ultrathin silica layer $(2 \mathrm{~nm})$ acts as proton transmitting, gas impermeable membrane [16,37]. Light absorbers are anchored on the outside of the silica shell where they are coupled to catalytic sites for $\mathrm{CO}_{2}$ reduction, while the inside surface of the $\mathrm{Co}_{3} \mathrm{O}_{4}$ nanotube is available for water oxidation catalysis. The concept of placing the proton transmitting, gas impermeable membrane between the sites of water oxidation and those of light absorption and $\mathrm{CO}_{2}$ reduction provides an opportunity to block access of oxidizing catalytic 
intermediates to reduction sites and structures that otherwise would result in back and corrosion reactions. Tight control of electron transfer across the insulating silica membrane is accomplished by embedded oligo para(phenylenevinylene) wire molecules featuring 3 aryl units (1,3-di((E)-styryl)benzene, abbreviated PV3, Figure 7(a). By selecting appropriate HOMO and LUMO energetics of light absorber, molecular wire and Co oxide catalyst as shown in Figure 7(b), fast hole hopping upon excitation of the light absorber is expected to efficiently drive water oxidation catalysis while the excited electron would be unable to populate the LUMO of the wire molecule, thus minimizing fast back electron transfer.

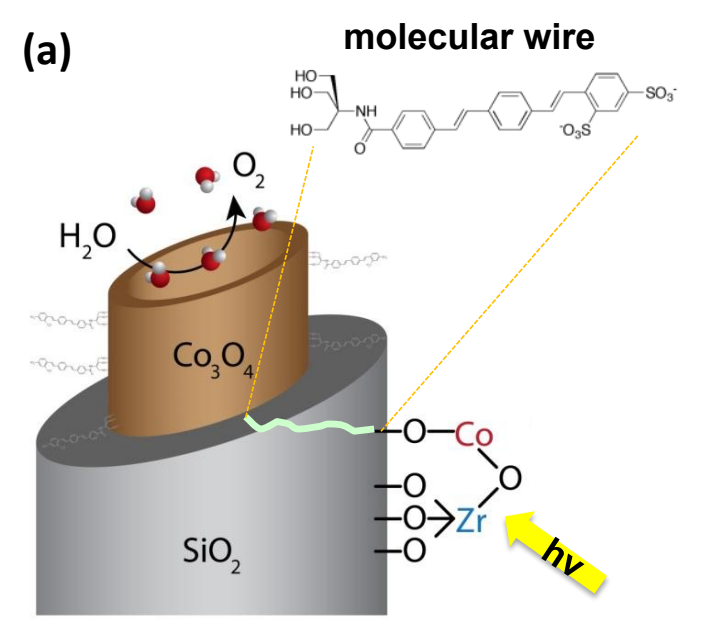

\section{(b)}

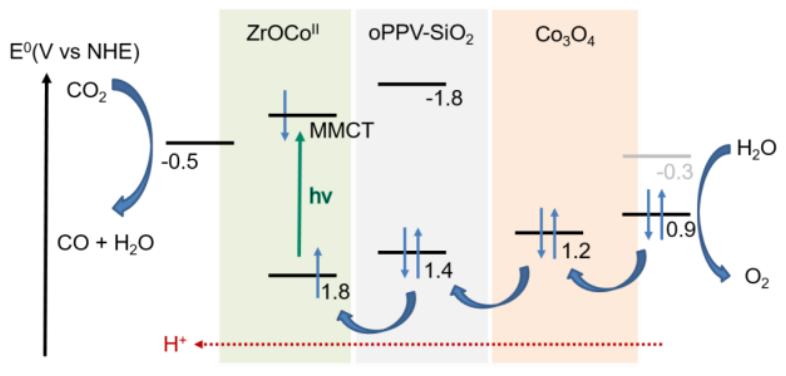

Fig. 7. Molecular wires for controlled charge transport embedded in nanometer thick silica membrane. (a) Schematic of $\mathrm{Co}_{3} \mathrm{O}_{4}-\mathrm{SiO}_{2}$ core-shell nanotube with $\mathrm{ZrOCo}$ light absorber coupled to $p$-oligo(phenylenevinylene) wire cast into amorphous, dense phase silica shell. (b) Energetics of HOMO and LUMO of light absorber, molecular wire, and catalyst. From Ref. [37], with permission.

To insure efficient transfer of holes from the excited light absorber to the $\mathrm{Co}_{3} \mathrm{O}_{4}$ catalyst surface and proper orientation in the membrane, a spider-like tripodal- $\mathrm{C}\left(\mathrm{CH}_{2}-\mathrm{O}\right)_{3}$ moiety $(1,3-$ dihydroxy-2-(hydroxymethyl)propan-2-yl)) was covalently anchored on the Co oxide surface [17]. Spider anchoring groups are known to impose perpendicular arrangement of molecules [38]. The perpendicular orientation of the PV3 molecule was further enforced by the negative 
charge of a terminal sulfonate group that exerts electrostatic repulsion from the negatively charged $\mathrm{Co}_{3} \mathrm{O}_{4}$ catalyst surface. Subsequent casting of the wires into dense phase silica by a solvothermal method [18] or by low temperature atomic layer deposition [39] completed the assembly of the new type of membrane for artificial photosynthesis. As also demonstrated by other groups for the case of silica encapsulation of dye molecules anchored on $\mathrm{TiO}_{2}$ surfaces [40], $\mathrm{SiO}_{2}$ grows as an amorphous dense phase solid selectively on the metal oxide surface in the free spaces between the attached organic molecules without depositing on or under the organic structures themselves, which is ideal for obtaining dense phase amorphous silica layers free of pinholes. We fine-tuned the thickness of the silica, which protects the organic from oxidative damage, to match the vertical dimension of the wire molecules.

Investigation by several spectroscopic methods showed that the silica embedded wire molecules maintained the structural integrity of the organic. For spherical core-shell nanoparticles consisting of a $4 \mathrm{~nm}$ diameter crystalline $\mathrm{Co}_{3} \mathrm{O}_{4}$ core surrounded by a $2 \mathrm{~nm} \mathrm{SiO}_{2}$ shell as shown in TEM images of Figure 8(a), FT-Raman spectroscopy revealed that the PV3 wire structure remains intact after silica casting (Figure 8b). These conclusions were confirmed by UV-vis spectra which showed only a minor spectral shift of the $\pi-\pi^{*}$ transition of PV3 at 360 nm upon embedding in low-dielectric silica [18]. 
(a)

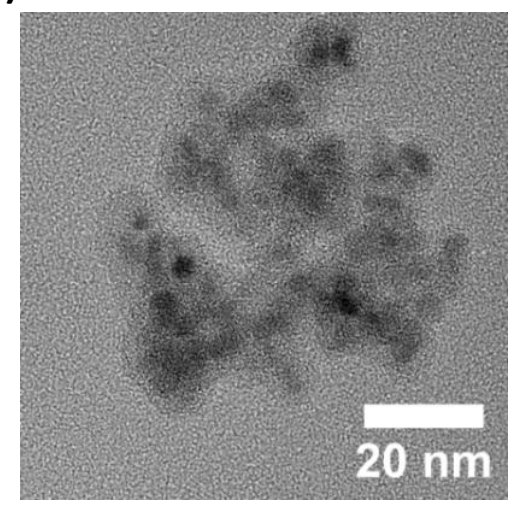

(b)

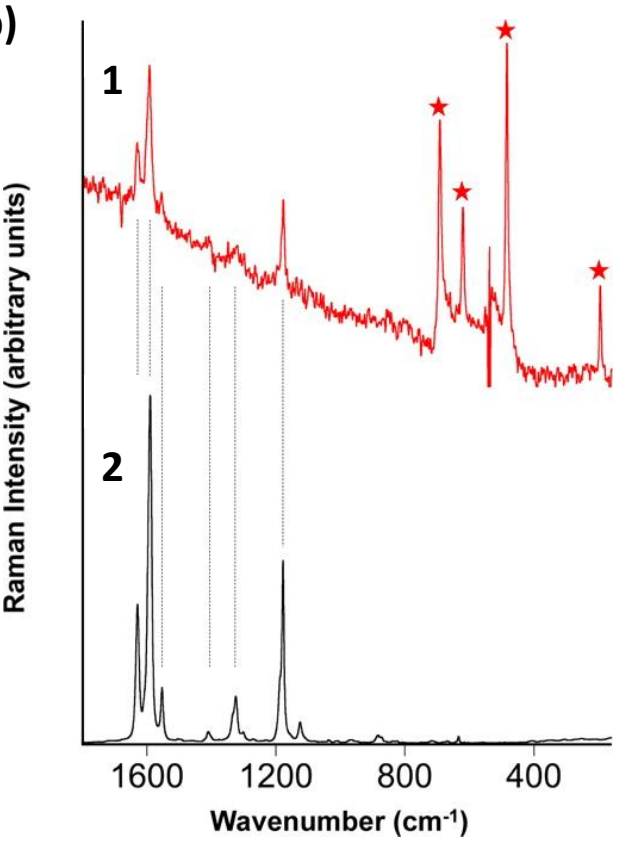

Fig. 8. $\mathrm{Co}_{3} \mathrm{O}_{4}-\mathrm{SiO}_{2}$ core-shell nanoparticles with embedded $\mathrm{PV} 3$ wire molecules. (a) TEM image. (b) Trace (1): FT-Raman spectra of $\mathrm{Co}_{3} \mathrm{O}_{4}-\mathrm{PV} 3-\mathrm{SiO}_{2}$ core-shell particles. Trace (2): Free PV3 molecules (powder). From Ref. [18], with permission.

\subsection{Charge transport properties}

Using aqueous colloids of the spherical core-shell nanoparticles, charge transport from a molecular light absorber on the outside to the Co oxide core on the inside was monitored by nanosecond absorption spectroscopy by the method depicted in Figure 9(a). Quenching of the transient bleach of $\left[\mathrm{Ru}\left(\mathrm{bpy}\left(\mathrm{CO}_{2} \mathrm{CH}_{3}\right)_{2}\right)_{3}\right]^{2+}$ at $470 \mathrm{~nm}$ upon excitation of the MLCT absorption of the $\mathrm{Ru}$ complex with an $8 \mathrm{~ns}$ pulse at $450 \mathrm{~nm}$ is observed in the presence of $\mathrm{Co}_{3} \mathrm{O}_{4}$ particles, but not in their absence (Figure 9b). The recovery of the bleach is caused by transfer of a hole from $\left[\mathrm{Ru}\left(\mathrm{bpy}\left(\mathrm{CO}_{2} \mathrm{CH}_{3}\right)_{2}\right)_{3}\right]^{3+}$ (generated by electron transfer from the excited Ru complex to an electron acceptor $\left(\left[\mathrm{Co}\left(\mathrm{NH}_{3}\right)_{5} \mathrm{Cl}\right]^{2+}\right)$ upon collisional encounter with a $\mathrm{Co}_{3} \mathrm{O}_{4}-\mathrm{PV} 3-\mathrm{SiO}_{2}$ particle. The diffusion controlled bimolecular rate constant of $8 \times 10^{10} \mathrm{~L} \mathrm{~mol}^{-1} \mathrm{~s}^{-1}$, combined with the absence of buildup of wire radical cation signal at $600 \mathrm{~nm}$ (Figure 9c and 9d) indicates an upper 
limit of a $\mu$ s for hole transfer from the light absorber to the $\mathrm{Co}_{3} \mathrm{O}_{4}$ particle (given that the absorption of the hole on PV3 at $600 \mathrm{~nm}$ is below the detection limit, an upper limit equal to the observed absorbance noise is assumed). Ultrafast optical studies using an electrostatically adsorbed free-base porphyrin currently in progress in our lab point to sub-nanosecond hole transfer from light absorber through the embedded molecular wires to the catalyst surface [41]. While such fast hole transfer between a molecular light absorber and metal oxide catalyst is unprecedented, it is interesting to note that in the field of dye sensitized semiconductor electrodes, ultrafast hole injection from an excited light absorber (coumarin or perylene-3,4dicarboximide) to a metal oxide (p-typeNiO) has been reported [42-44]. Hammarstroem found $200 \mathrm{fs}$ transit time for hole transfer from the excited coumarin compound C343 adsorbed via carboxyl group to $\mathrm{NiO}$, which recently enabled efficient electron transfer from the excited dye to a co-adsorbed artificial hydrogenase [45].

(a)

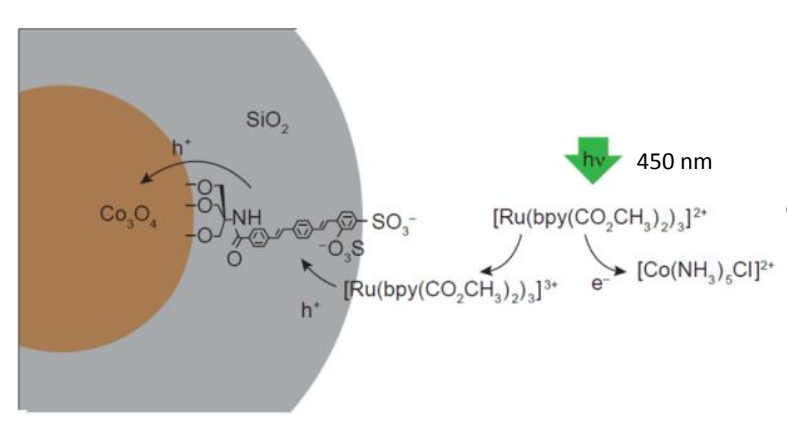

(c)

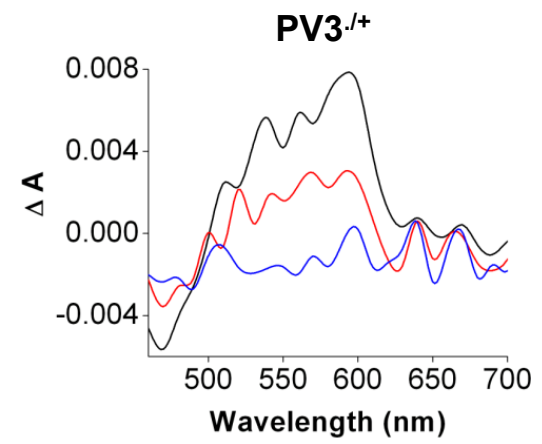

(b)

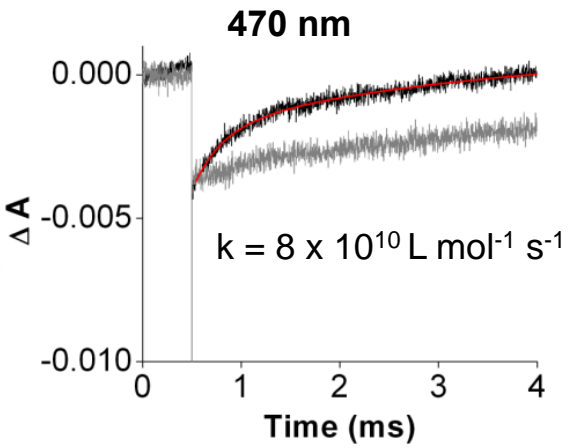

(d)

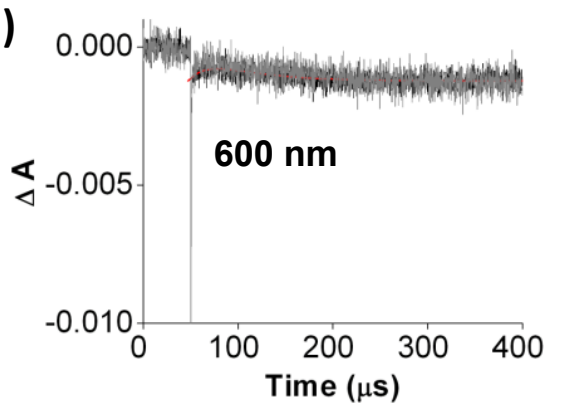


Fig. 9. Transient optical spectroscopy of hole transfer to silica embedded molecular wire. (a) Schematic of visible light induced hole transfer process from sensitizer on the outside to $\mathrm{Co}_{3} \mathrm{O}_{4}$ particle on the inside of the spherical core-shell particle. (b) Black trace: Recovery of the bleach of the $\mathrm{Ru}$ sensitizer complex $(470 \mathrm{~nm})$ upon hole injection into embedded wire molecules. Grey trace: $\mathrm{Co}_{3} \mathrm{O}_{4}-\mathrm{SiO}_{2}$ particles with no wires. (c) Transient absorption spectra of PV3 wire anchored on silica surface (time slices at 40, 200, $800 \mu$ s after hole injection). (d) Transient absorption measurement at $600 \mathrm{~nm}$ of $\mathrm{Co}_{3} \mathrm{O}_{4}-\mathrm{PV} 3-\mathrm{SiO}_{2}$ particle. From Refs.[17] and [18], with permission.

For the quantitative evaluation of charge flux across the embedded wire molecules and measurement of the proton transmission through the silica membrane, we conducted electrochemical or photoelectrochemical measurements using $\mathrm{cm}^{2}$-sized planar $\mathrm{Co}_{3} \mathrm{O}_{4}-\mathrm{PV}_{3}-\mathrm{SiO}_{2}$ constructs. Co oxide layers of $7 \mathrm{~nm}$ thickness were deposited on a Pt electrode by mild temperature (plasma enhanced) ALD [39]. Following covalent anchoring of PV3 wire molecules on the Co oxide surface by tripods as described above, a $2.3 \mathrm{~nm}$ thick layer of silica was cast around the wire molecules, also by ALD. Imaging by scanning transmission electron microscopy/energy dispersive X-ray spectroscopy (STEM EDX) revealed uniform and conformal Co oxide and silica layers, as shown in Figure 10(a). Sulfur EDX allowed us to image the wire molecules by virtue of the sulfoxide group of PV3, indicating a density of 1 wire per $\mathrm{nm}^{2}$, which corresponds to 0.2 monolayer coverage (Figure 10a). Spectroscopic confirmation of intact organic wires upon silica casting was further obtained by XPS of $\mathrm{S}$ ( $\mathrm{SO}_{3}{ }^{-}$group) and $\mathrm{N}$ (amide bond) shown in Figure 10(b), and by observation of a few of the most intense vibrational modes of PV3 by grazing angle ATR FT-IR [39]. 
(a)

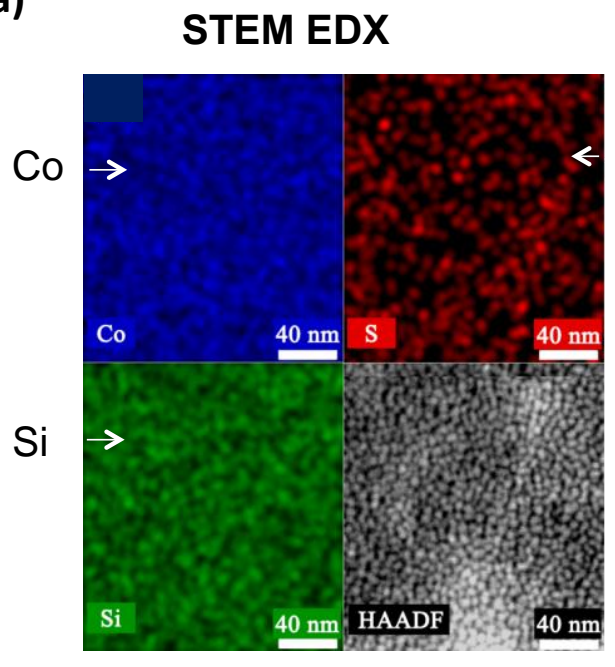

(b) XPS

$\mathrm{SO}_{3}-$ group of wire molecule

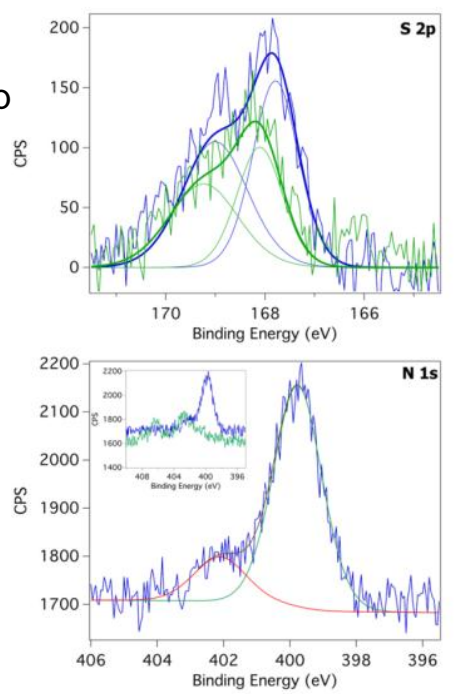

Fig. 10. Spectroscopic characterization of planar $\mathrm{Co}_{3} \mathrm{O}_{4}-\mathrm{SiO}_{2}$ constructs with embedded PV3 wires. (a) EDX maps of Co, top left; Si, bottom left; S, top right; Dark field image, bottom right. (b) XPS of planar $\mathrm{Co}_{3} \mathrm{O}_{4}$-PV3 sample before (blue) and after deposition of $2.3 \mathrm{~nm}$ of silica (green). Sulfur S (2p) XPS of $\mathrm{SO}_{3}{ }^{-}$substituent of wire molecules (top). Nitrogen N (1s) XPS of amide group of wire (bottom). The small peak at $402 \mathrm{eV}$ is due to residual HTCU reagent. Smooth traces show spectral deconvolutions. From Ref. [39], with permission.

Photoelectrochemical measurements in short circuit configuration using visible light sensitizers with selected redox properties demonstrated the tight control of electron transfer exerted by the electronic properties of the embedded wire molecules. For the $\left[\mathrm{Ru}(\mathrm{bpy})_{3}\right]^{2+} / \mathrm{S}_{2} \mathrm{O}_{8}{ }^{2-}$ photosensitization system that generates $\left[\mathrm{Ru}(\mathrm{bpy})_{3}\right]^{3+}$ with a redox level well aligned with the HOMO of PV3 [46], a $476 \mathrm{~nm}$ induced current of 27 electrons s${ }^{-1}$ per wire molecule is observed (Figure 11a and 11b). The capacity of wire molecules to transfer charges exceeds this rate by at least an order of magnitude [47]. Hence, charge transport between light absorber and catalyst across the embedded wires will not pose a kinetic bottleneck even at maximum solar intensity. When using a photosensitizer with redox potential that was not aligned with HOMO or LUMO of PV3, no current was detected. This was the case for the radical anion of Sn porphyrin 
generated by visible light sensitization of the sensitizer in the presence of trimethylamine donor, with a redox potential that lies inside the HOMO-LUMO gap of PV3 [48]. Hence, the passage of electrons or holes across the insulating ultrathin silica membrane is controlled by the orbital energetics of the wires. The precise energetic control of the electron (or hole) flow across the membrane confirms the absence of pinholes of the ultrathin silica layer, which was further proven by cyclic voltammetry using the ferrocene/ferrocenium couple (Figure 11c).
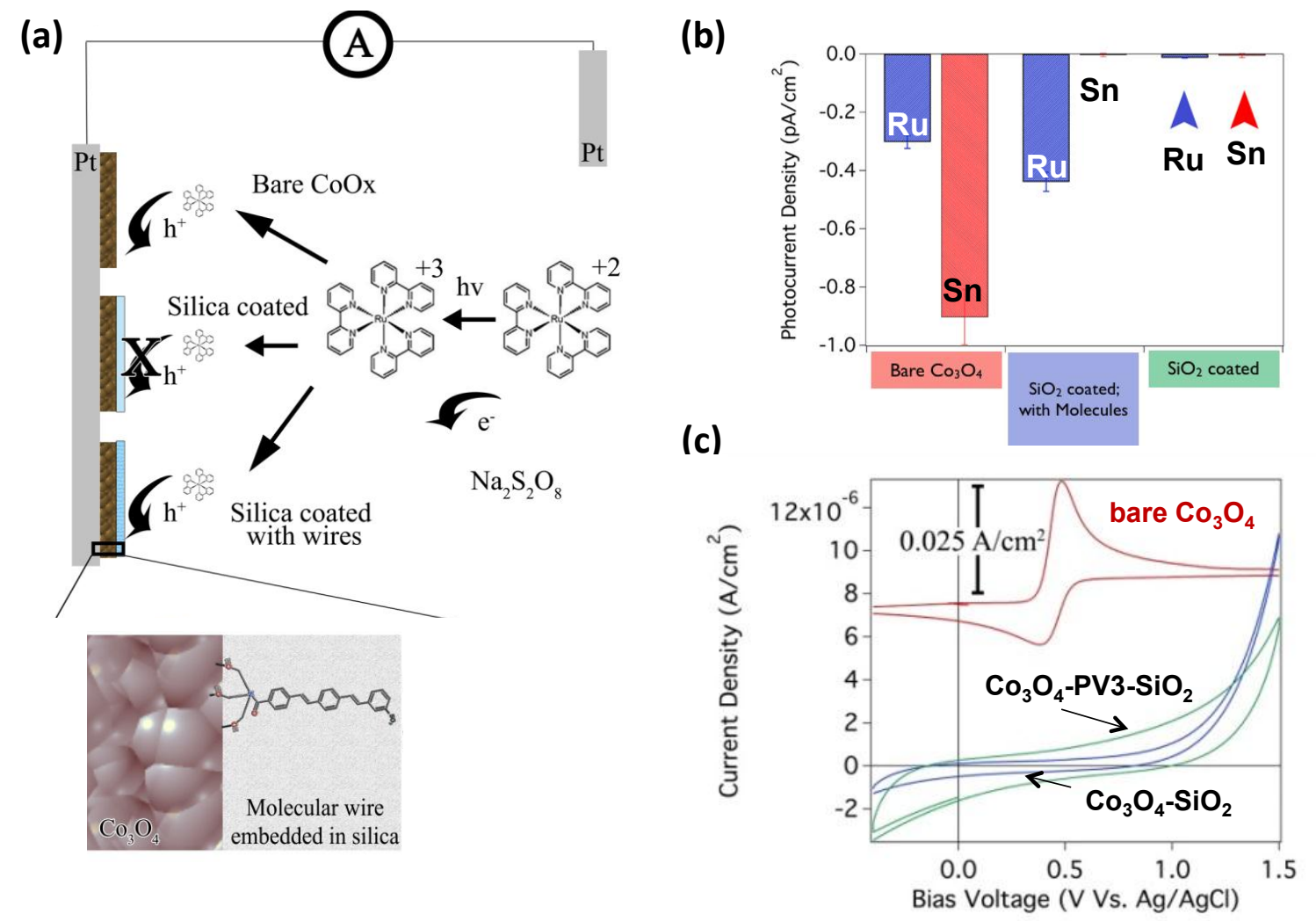

Fig. 11. Photoelectrochemical and CV measurements of charge transport across silica membrane with embedded wires. (a) Schematic of visible light sensitized short circuit photocurrent measurement using $\mathrm{Ru}(\mathrm{bpy})_{3}$-persulfate (labeled $\mathrm{Ru}$ ) and $\mathrm{Sn}$ porphyrin-triethylamine systems (labeled Sn). (b) Photocurrent observed for hole injection into bare Co oxide, Co oxide coated with $\mathrm{SiO}_{2}$-PV3 membrane, and Co oxide coated with silica only. (c) $\mathrm{CV}$ of ferrocene (in acetonitrile containing $0.1 \mathrm{M}$ tert-butylammonium perchlorate) using bare $\mathrm{Co}_{3} \mathrm{O}_{4}$ on Pt electrode (red curve, offset for clarity), $\mathrm{Co}_{3} \mathrm{O}_{4}-\mathrm{PV} 3-\mathrm{SiO}_{2}$ (blue curve), and $\mathrm{Co}_{3} \mathrm{O}_{4}-\mathrm{SiO}_{2}$ (green curve). From Ref. [39], with permission. 
In addition to the desired electron transfer properties between light absorber and water oxidation catalyst enabled by the wire linkage across the membrane, the proton transmission property required for transferring $\mathrm{H}^{+}$generated by $\mathrm{H}_{2} \mathrm{O}$ oxidation on one side to the $\mathrm{CO}_{2}$ reduction sites for fuel formation on the other needs to be considered. Proton transmission was established and quantified by cyclic voltammetry using the planar silica layers on Pt as working electrode [16]. At $\mathrm{pH} 4$, a flux of 2.5 protons per s $\mathrm{nm}^{-1}$ was measured for a membrane of 3.8 $\mathrm{nm}$ thickness. The silica depth dependence of the overvoltage for proton transmission is 25 $\mathrm{mV} / \mathrm{nm}$ for thickness beyond $4 \mathrm{~nm}$, and the proton transmission properties can be enhanced if needed by light doping with $\mathrm{P}$ or Ti [49]. Impermeability to $\mathrm{O}_{2}$, another critical property of the membrane was probed by $\mathrm{CV}$ measurements. Complete blocking of $\mathrm{O}_{2}$ was confirmed for a silica layer thickness of $2 \mathrm{~nm}[16]$.

\section{Molecular light absorber-polyoxometalate catalyst systems}

An interesting case of oxygen evolving photocatalytic systems consisting of a molecular light absorber coupled to a metal oxide cluster for water oxidation are polyoxometalates (POM) because here even the metal oxide cluster is molecularly defined. Very fast hole transfer on the time scale of a nanosecond for the initial oxidation step was reported by Hill for a Ru polyoxotungstate $\left[\left\{\mathrm{Ru}_{4} \mathrm{O}_{4}(\mathrm{OH})_{2}\left(\mathrm{H}_{2} \mathrm{O}\right)_{4}\right\}\left(\gamma-\mathrm{SiW}_{10} \mathrm{O}_{36}\right)_{2}\right]^{10-}$ catalyst for oxygen evolution coupled to a metal polypyridine sensitizer $\left[\mathrm{Ru}(\mathrm{bpy})_{2}(\mathrm{dpbpy})\right]^{2+}\left(\mathrm{dpbpy}=4,4^{\prime}\right.$-diphosphonic acid-2,2'bipyridyl) [50]. This finding built on preliminary nanosecond photosensitization studies by the same group [51] and by the group of Bonchio that showed bimolecular rate constants within one order of magnitude of diffusion controlled rate for hole transfer from $\mathrm{Ru}(\mathrm{bpy})_{3}$ type sensitizer to the above POM catalysts [52,53]. The work opens up designs of systems for which charge 
transfer for driving the water oxidation catalysis can outcompete recombination processes. For the example shown in Figure 12, the components of the molecular light absorber-POM assembly are adsorbed on $\mathrm{TiO}_{2}$ or $\mathrm{SnO}_{2}$ anode. The very large electrostatic interaction of dye and $\mathrm{POM}$ molecule due to the high negative charge of the latter and the positive charge of the former may be an important factor for the high rate of hole transfer.

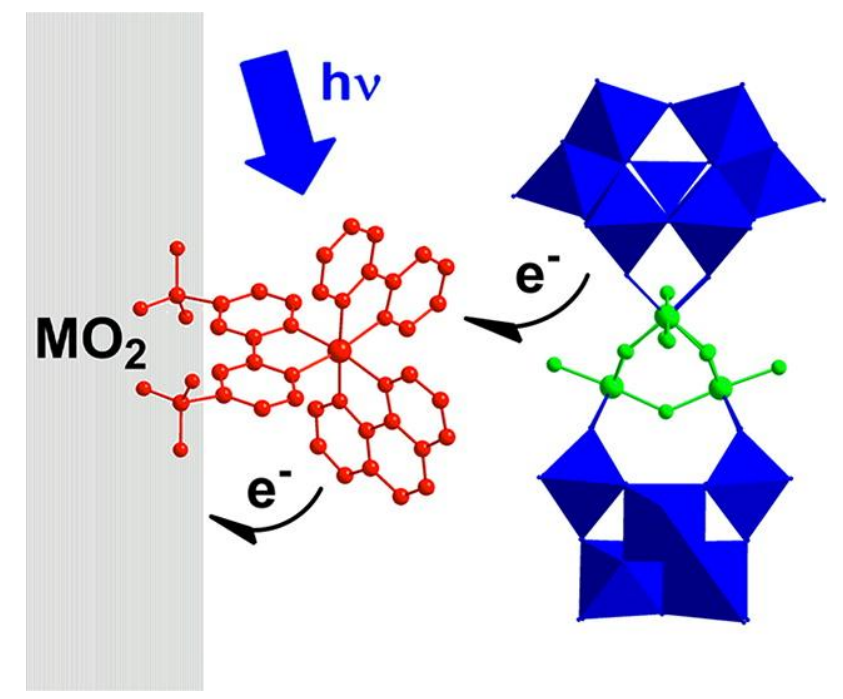

Fig. 12. Fast hole transfer of one nanosecond for the initial oxidation step for Ru polyoxotungstate $\left[\left\{\mathrm{Ru}_{4} \mathrm{O}_{4}(\mathrm{OH})_{2}\left(\mathrm{H}_{2} \mathrm{O}\right)_{4}\right\}\left(\gamma-\mathrm{SiW}_{10} \mathrm{O}_{36}\right)_{2}\right]^{10-}$ catalyst for oxygen evolution (blue) coupled to a metal polypyridine sensitizer $\left[\mathrm{Ru}(\mathrm{bpy})_{2}(\mathrm{dpbpy})\right]^{2+}$ (dpbpy $=4,4^{\prime}$-diphosphonic acid-2,2'-bipyridyl) (red). From Ref. [50], with permission.

Transition metal substituted POM complexes themselves can also serve as robust, allinorganic charge transfer light absorbers. A complex of composition $\left[\mathrm{P}_{4} \mathrm{~W}_{35} \mathrm{O}_{124}\left\{\mathrm{Re}(\mathrm{CO})_{3}\right\}_{2}\right]^{16-}$ consisting of an interacting pair of Wells-Dawson polyoxometalate $\left[\alpha_{2}-\mathrm{P}_{2} \mathrm{~W}_{17} \mathrm{O}_{61}\right]^{10-}$ units, each with featuring a $\left[\operatorname{Re}(\mathrm{CO})_{3}\right]^{+}$complex linked to the $\mathrm{POM}$ by $\mathrm{W}^{\mathrm{VI}}-\mathrm{O}-\mathrm{Re}^{\mathrm{I}}$ bridges was found to possess an intense, visible light absorbing $\mathrm{Re}^{\mathrm{I}}-\mathrm{O}-\mathrm{W}^{\mathrm{VI}} \rightarrow \mathrm{Re}^{\mathrm{II}}-\mathrm{O}-\mathrm{W}^{\mathrm{V}}$ metal-to-POM charge transfer transition [54-56]. Oxidation state changes in the excited state were revealed by ultrafast optical and infrared spectroscopy (the latter for monitoring Re oxidation state sensitive CO ligand 
vibrational absorptions). While very short lived ( $<2 \mathrm{ps})$, subsequently discovered Co containing Keggin POMs like $\left[\mathrm{Co}^{\mathrm{II}} \mathrm{W}_{12} \mathrm{O}_{40}\right]^{6-}$ featuring $\mathrm{Co}^{\mathrm{II}}-\mathrm{O}-\mathrm{W}^{\mathrm{VI}} \rightarrow \mathrm{Co}^{\mathrm{III}}-\mathrm{O}-\mathrm{W}^{\mathrm{V}}$ metal-to-POM transition showed orders of magnitude longer lifetime of $1.7 \mathrm{~ns}$ [57]. The extended lifetime renders the unit potentially suitable for driving a multi-electron catalyst for water oxidation and may be attributed to structural distortion of the Co coordination environment upon excitation that results in decreased orbital overlap of the Co with the reduced POM unit. This opens the possibility for allinorganic POM -based molecular light absorber-catalyst systems for visible light water oxidation.

\section{Conclusions}

Molecular light absorbers offer precise control of electronic properties and atomically defined attachment to metal oxide particles. Recent improvement of designs for the coupling of metal oxide catalysts with molecular chromophores, combined with the direct spectroscopic observation and kinetic evaluation of charge transfer processes has resulted in substantial progress towards more efficient photosystems for oxygen evolution. An important development is the introduction of relays for mitigating the disparate rates of charge transfer between light absorber and catalyst on the one hand, and back transfer of separated electrons, on the other. Transient optical measurements reveal charge transfer rates between light absorber and oxide catalysts that vary by many orders of magnitude, understanding of which will be critical for guiding further efficiency improvements. Spatially directed assembly by engaging charge transfer chromophores for driving photodeposition of metal oxide clusters enables the development of all-inorganic polynuclear units for water oxidation. For one system, simultaneous coupling to carbon dioxide reduction was demonstrated. For designs that separate 
water oxidation catalysis from molecular light absorber by a membrane, molecular wires with matched redox properties embedded in a nanoscale silica layer open up an approach that maintains molecularly defined linkage between the components. Nanomaterials chemistry offers rich opportunities for exploring new approaches for the coupling metal oxide catalysts with molecular light absorbers in a most efficient manner.

\section{Acknowledgments}

This work was supported by the Director, Office of Science, Office of Basic Energy Sciences, Division of Chemical, Geological and Biosciences of the U.S. Department of Energy under Contract No. DE-AC02-05CH11231. 


\section{References}

[1] F. Jiao, H. Frei, Angew. Chem. Int. Ed. 48 (2009) 1841-1844.

[2] F. Jiao, H. Frei, Chem. Commun. 46 (2010) 2920-2922.

[3] F. Jiao, H. Frei, Energy Environ. Sci. 3 (2010) 1018-1027.

[4] M. Grzelczak, J. Zhang, J. Pfrommer, J. Hartmann, M. Driess, M. Antonietti, X. Wang, ACS Catal. 3 (2013) 383-388.

[5] S. Yusuf, F. Jiao, ACS Catal. 2 (2012) 2753-2760.

[6] A.J. Esswein, M.J. McMurdo, P.N. Ross, A.T. Bell, T.D. Tilley, J. Phys. Chem. 113 (2009) 15068-15072.

[7] V.B.R. Boppana, F. Jiao, Chem. Commun. 47 (2011) 8973-8975.

[8] J.D. Blakemore, H.B. Gray, J.R. Winkler, A.M. Mueller, ACS Catal. 3 (2013) 24972500.

[9] G.S. Hutchings, Y. Zhang, J. Li, B.T. Yonemoto, X. Zhou, K. Zhu, F. Jiao, J. Am. Chem. Soc. 137 (2015) 4223-4229.

[10] P.W. Menezes, A. Indra, D. Gonzalez-Flores, N.R. Saharaie, I. Zaharieva, M. Schwarze, P. Strasser, H. Dau, M. Driess, ACS Catal. 5 (2015) 2017-2027.

[11] H. Tuysuz, Y.J. Hwang, S.B. Khan, A.M. Asiri, P. Yang, Nano Res. 6 (2013) 47-54.

[12] Y.J. Sa, K. Kwon, J.Y. Cheon, F. Kleitz, S. H. Joo, J. Mater. Chem. A 1 (2013) 999210001.

[13] M.W. Kanan, D.G. Nocera, Science 231 (2008) 1072-1075.

[14] D.G. Nocera, Acc. Chem. Res. 45 (2012) 767-776.

[15] http://rredc.nrel.gov/solar/spectra/am1.5

[16] G. Yuan, A. Agiral, N. Pellet, H. Frei, Faraday Discuss. 176 (2014) 233-249. 
[17] H.S. Soo, A. Agiral, A. Bachmeier, H. Frei, J Am. Chem. Soc. 134 (2012) 17104-17116.

[18] A. Agiral, H.S. Soo, H. Frei, Chem. Mater. 25 (2013) 2264-2273.

[19] M.L. Macnaughtan, H.S. Soo, H. Frei, J. Phys. Chem. C 118 (2014) 7874-7885.

[20] W. Kim, G. Yuan, B.A. McClure, H. Frei, J. Am. Chem. Soc. 136 (2014) 11034-11042.

[21] W. Kim, E. Edri, H. Frei, Acc. Chem. Res. 49 (2016) 1634-1645.

[22] B.A. McClure, Frei H. J. Phys. Chem. C 118 (2014) 11601-11611.

[23] T. Cuk, W.W. Weare, H. Frei, J. Phys. Chem. C 114 (2010) 9167-9172.

[24] G. Katsoukis, H. Frei, in preparation.

[25] H. Han, H. Frei, J. Phys. Chem. C 112 (2008) 16156-16159.

[26] N.D. Morris, M. Suzuki, T.E. Mallouk, J. Phys. Chem. A 108 (2004) 9115-9119.

[27] A. Harriman, I.J. Pickering, J.M. Thomas, P.A. Christensen, J. Chem. Soc. Faraday Trans. I 84 (1988) 2795-2806.

[28] T. Nakagawa, N.S. Bjorge, R.W. Murray, J. Am. Chem. Soc. 131 (2009) 15578-15579.

[29] R. Nakamura, H. Frei, J. Am. Chem. Soc. 128 (2006) 10668-10669.

[30] H. Huang, J. Lin, G. Zhu, Y. Weng, X. Wang, X. Fu, J. Long, Angew. Chem. Int. Ed. 55 (2016) 8314-8318.

[31] W. Kim, H. Frei, ACS Catal. 5 (2015) 5627-5635.

[32] W.J. Youngblood, S.H.A. Lee, Y. Kobayashi, E. Hernandez-Pagan, P.G. Hoertz, T.A. Moore, A.L. Moore, D. Gust, T.E. Mallouk, J. Am. Chem. Soc. 131 (2009) 926-927.

[33] J.R. Swierk, T.E. Mallouk, Chem. Soc. Rev. 42 (2013) 2357-2387.

[34] Y. Zhao, J.R. Swierk, J.D. Megiatto, B. Sherman, W.J. Youngblood, D. Qin, D.M. Lentz, A.L. Moore, T.A. Moore, D. Gust, T.E. Mallouk, Proc. Natl. Acad. Sci. U.S.A. 109 (2012) 15612-15616. 
[35] J.D. Megiatto, D.D. Mendez-Hernandez, M.E. Tejeda-Ferrari, A.L. Teillout, M.J. Llandsola-Portoles, G. Kodis, O.G. Poluektov, T. Rajh, V. Mujica, T.L. Groy, D. Gust, T.A. Moore, A.L. Moore, Nature Chem. 6 (2014) 423-428.

[36] J.R. Swierk, N.S. McCool, T.E. Mallouk, J. Phys. Chem. C 119 (2015) 13858-13867.

[37] W. Kim, B.A. McClure, E. Edri, H. Frei, Chem. Soc. Rev. 45 (2016) 3221-3243.

[38] E. Gallopini, Coord. Chem. Rev. 248 (2004) 1283-1297.

[39] E. Edri, H. Frei, J. Phys. Chem. C 119 (2015) 28326-28334.

[40] H.J. Son, X. Wang, C. Prasittichai, N.C. Jeong, T. Aaltonen, R.G. Gordon, J.T. Hupp, J. Am. Chem. Soc. 134 (2012) 9537-9540.

[41] E. Edri, J.K. Cooper, I.S. Sharp, D. Guldi, H. Frei, J. Am. Chem. Soc. (2017), submitted.

[42] A. Morandeira, G. Boschloo, A. Hagfeldt, L. Hammarstroem, J. Phys. Chem. B 109 (2005) 19403-19410.

[43] A. Morandeira, G. Boschloo, A. Hagfeldt, L. Hammarstroem, J. Phys. Chem. C 112 (2008) 9530-9537.

[44] R.J. Kamire, M.B. Majewski, W.L. Hoffeditz, B.T. Phelan, O.K. Farha, J.T. Hupp, M.R. Wasielewski, Chem. Sci. 8 (2017) 541-549.

[45] A.M. Brown, L.J. Antila, M. Mirmohades, S. Pullen, S. Ott, L. Hammarstroem. J. Am. Chem. Soc. 138 (2016) 8060-8063.

[46] W.B. Davis, M.A. Ratner, M.R. Wasielewski, Chem. Phys. 281 (2002) 333-346.

[47] H.D. Sikes, J.F. Smalley, S.P. Dudek, A.R. Cook, M.D. Newton, C.E.D. Chidsey, S.W. Feldberg, Science 291 (2001) 1519-1523.

[48] R.L. Lemke, C.R. Lorenz, Recent Res. Dev. Electroanal. Chem. 1 (1999) 73-89.

[49] C.W. Moore, J. Li, P.A. Kohl, J. Electrochem. Soc. 152 (2005) A1606-A1612. 
[50] X. Xiang, J. Fielden, W. Rodriguez-Cordoba, Z. Huang, N. Zhang, D.G. Luo, D.G. Musaev, T. Lian, C.L. Hill, J. Phys. Chem. C 117 (2013) 918-926.

[51] Z. Huang, Y.V. Geletii, D.G. Musaev, C.L. Hill, T. Lian, Ind. Eng. Chem. Res. 51 (2012) 11850-11859.

[52] M. Orlandi, R. Argazzi, A. Sartorel, M. Carraro, G. Scorrano, M. Bonchio, F. Scandola, Chem. Commun. 46 (2010) 3152-3154.

[53] M. Natali, M. Orlandi, S. Berardi, S. Campagna, M. Bonchio, A. Sartorel, F. Scandola, Inorg. Chem. 51 (2012) 7324-7331.

[54] C. Zhao, Z. Huang, W. Rodriguez-Cordoba, C.S. Kambara, K.P. O’Halloran, K.I. Hardcastle, D.G. Musaev, T. Lian, C.L. Hill, J. Am. Chem. Soc. 133 (2011) 2013420137.

[55] C. Zhao, W. Rodriguez-Cordoba, A.L. Kaledin, Y. Yang, Y.V. Geletii, T. Lian, D.G. Musaev, C.L. Hill, Inorg. Chem. 52 (2013) 13490-13495.

[56] C. Zhao, C.S. Kambara, Y. Yang, A.L. Kaledin, D.G. Musaev, T. Lian, C.L. Hill, Inorg. Chem. 52 (2013) 671-678.

[57] E.N. Glass, J. Fielden, A.L. Kaledin, D.G. Musaev, T. Lian, C.L. Hill, Chem. Eur. J. 20 (2014) 4297-4307. 


\section{Description}

Recent advances in the efficient coupling of molecular light absorbers and robust metal oxide water oxidation catalysts for incorporation into artificial photosynthetic systems are reviewed.

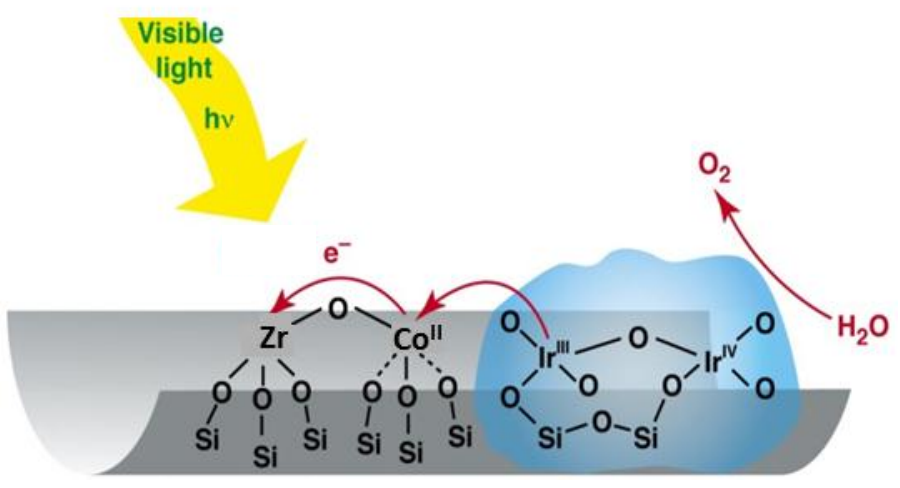

